\title{
Longitudinal Motion Control of AUV Based on Fuzzy Sliding Mode Method
}

\author{
Duo Qi, Jinfu Feng, and Jian Yang \\ Aeronautics and Astronautics Engineering College, Air Force Engineering University, Xian 710038, China \\ Correspondence should be addressed to Duo Qi; qi33song@sina.com
}

Received 22 October 2015; Accepted 21 January 2016

Academic Editor: Lifeng Ma

Copyright (C) 2016 Duo Qi et al. This is an open access article distributed under the Creative Commons Attribution License, which permits unrestricted use, distribution, and reproduction in any medium, provided the original work is properly cited.

\begin{abstract}
According to the characteristics of AUV movement, a fuzzy sliding mode controller was designed, in which fuzzy rules were adopted to estimate the switching gain to eliminate disturbance terms and reduce chattering. The six-degree-of-freedom model of AUV was simplified and longitudinal motion equations were established on the basis of previous research. The influences of first-order wave force and torque were taken into consideration. The REMUS was selected to simulate the control effects of conventional sliding mode controller and fuzzy sliding mode controller. Simulation results show that the fuzzy sliding mode controller can meet the requirements and has higher precision and stronger antijamming performances compared with conventional sliding mode controller.
\end{abstract}

\section{Introduction}

Nowadays the ocean space is an important competition field of military and economic powers in the world, and many countries are vigorously developing deep sea exploration technology. As an intercrossed subject of ocean engineering and robot technology, autonomous underwater vehicles (AUV) are playing increasingly significant roles in underwater activities, such as offshore oil exploitation, underwater target search, marine science research, and military application [1-5].

The stable and efficient control of AUV is very difficult for its inherent highly nonlinear, uncertain hydrodynamic parameters and external disturbances. Wang et al. [6] adopted S-surface control method to simulate the heading control and depth control of a mini AUV, and, furthermore, they simulated long distance traveling following a planned path. The results showed that the AUV has good spatial maneuverability and verified the feasibility and reliability of control method. Ma and Cui [7] proposed a robust pathfollowing control method for nonlinear and underactuated AUV based on a fuzzy hybrid control strategy. Jia et al. [8] presented a nonlinear iterative sliding mode controller based on the virtual guide method. It can decrease the static error and overshoot and achieves high tracking precision. Sahu and Subudhi [9] developed an adaptive control law for the AUV to track the desired trajectory and verified the stability of the controller using Lyapunov's direct method. The simulation results demonstrate that the controller is feasible for the tracking of uncertain parameters model. Lapierre and Soetanto [10] designed a new backstepping controller, which can get rid of the limits of initial conditions and make the tracking error converge to zero.

The sliding mode control has been successfully applied to dynamic positioning and motion control of underwater vehicle $[11,12]$, due to its simple algorithm, robustness against modeling imprecision, and external disturbances. However, the discontinuous switching characteristics of sliding mode control will cause chattering, which not only affects the control accuracy but also degrades the system performance and even severely damages the control units. Many researchers have put forward solutions to eliminate the chattering phenomenon from different angles, such as adaptive method [13], neural network method [14], feedback linearization method [15], and fuzzy method [16]. According to the experience, a proper switching gain can reduce chattering [17]. The fuzzy control has many advantages; for example, it needs no accurate mathematical model and has good robustness. 
TABLE 1: Motion mode and attitude parameters of AUV.

\begin{tabular}{|c|c|c|c|c|}
\hline $\begin{array}{l}\text { Degree of } \\
\text { freedom }\end{array}$ & Motion modes & $\begin{array}{c}\text { Force/torque } \\
\text { (in the body-fixed } \\
\text { coordinate) }\end{array}$ & $\begin{array}{c}\text { Linear velocity/angular } \\
\text { velocity } \\
\text { (in the body-fixed coordinate) }\end{array}$ & $\begin{array}{c}\text { Location/Euler angles } \\
\text { (in the earth-fixed } \\
\text { coordinate) }\end{array}$ \\
\hline 1 & Back/forward (movement along the $x$-axis) & $F_{x}$ & $u$ & $x$ \\
\hline 2 & Sway (movement along the $y$-axis) & $F_{y}$ & $v$ & $y$ \\
\hline 3 & Lift/dive (movement along the $z$-axis) & $F_{z}$ & $w$ & $z$ \\
\hline 4 & Roll (rotation along the $x$-axis) & $M_{x}$ & $p$ & $\phi$ \\
\hline 5 & Pitch (rotation along the $y$-axis) & $M_{y}$ & $q$ & $\theta$ \\
\hline 6 & Yaw (rotation along the $z$-axis) & $M_{z}$ & $r$ & $\psi$ \\
\hline
\end{tabular}

The fuzzy sliding mode control combines the advantages of sliding mode control and fuzzy control and can make discrete control signals continuous to reduce chattering effectively.

The main contribution of this paper is to design a fuzzy sliding mode controller for the longitudinal motion control of AUV with the consideration of first-order wave force and torque. Based on the conventional sliding mode control, fuzzy rules are adopted to estimate the switching gain to eliminate disturbance terms and reduce chattering. The simulation results show that the fuzzy sliding mode controller can meet the requirements. Compared with conventional sliding mode controller, it has higher precision and stronger antijamming performances, which has good practical values.

\section{Longitudinal Motion Model of AUV and Wave Disturbance}

Earth-fixed coordinate and AUV body-fixed coordinate are shown in Figure 1. Six-DOF kinematic modes and attitude parameters are defined in the coordinate system as shown in Table 1.

According to the parameters in Table 1, we define vectors as follows: $\eta_{1}=(x, y, z)^{T}, \eta_{2}=(\phi, \theta, \psi)^{T}, \eta=\left(\eta_{1}, \eta_{2}\right)^{T}$, $\tau_{1}=\left(F_{x}, F_{y}, F_{z}\right)^{T}, \tau_{2}=\left(M_{x}, M_{y}, M_{z}\right)^{T}, \tau=\left(\tau_{1}, \tau_{2}\right)^{T}, V=$ $(u, v, w)^{T}, \omega=(p, q, r)^{T}, v=(V, \omega)^{T}$, the center of gravity position is $r_{G}=\left(x_{g}, y_{g}, z_{g}\right)^{T}$, and the center of buoyancy position is $r_{B}=\left(x_{B}, y_{B}, z_{B}\right)^{T}$.

The longitudinal motion equations of AUV with respect to the body-fixed moving frame are described by a set of nonlinear differential equations as follows:

$$
\begin{aligned}
m\left(\dot{u}+w q-x_{g} q^{2}+z_{g} \dot{q}\right) & =F_{x}, \\
m\left(\dot{w}-u q-z_{g} q^{2}-x_{g} \dot{q}\right) & =F_{z}, \\
I_{y y} \dot{q}+m\left[z_{g}(\dot{u}+w q)-x_{g}(\dot{w}-u q)\right] & =M_{y} .
\end{aligned}
$$

Ignore all the high-order terms under the condition of low speed; the mathematical model above can be simplified as

$$
\begin{aligned}
m\left(\dot{u}+z_{g} \dot{q}\right) & =F_{x}, \\
m\left(\dot{w}-U q-x_{g} \dot{q}\right) & =F_{z}, \\
I_{y y} \dot{q}+m\left[z_{g} \dot{u}-x_{g}(\dot{w}-u q)\right] & =M_{y},
\end{aligned}
$$

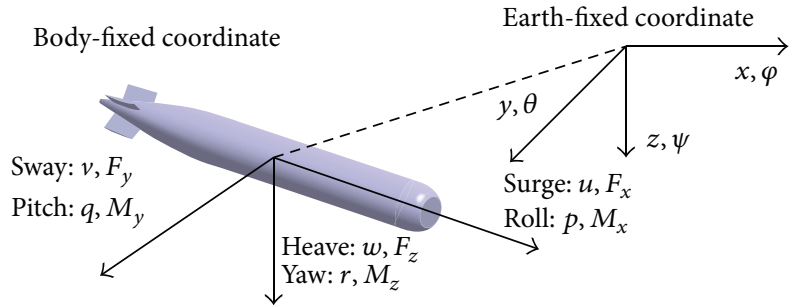

FigURE 1: Reference coordinates and 6-DOF coordinates of AUV.

where

$$
\begin{aligned}
F_{x} & =X_{\dot{u}} \dot{u}+X_{u} u+X_{q} q+X_{\theta} \theta, \\
F_{z} & =Z_{\dot{w}} \dot{w}+Z_{\dot{q}} \dot{q}+Z_{w} w+Z_{q} q+Z_{\delta_{s}} \delta_{s}, \\
M_{y} & =M_{\dot{w}} \dot{w}+M_{\dot{q}} \dot{q}+M_{w} w+M_{q} q+M_{\delta_{s}} \delta_{s},
\end{aligned}
$$

and $X_{\dot{u}}, Z_{\dot{w}}, M_{\dot{w}} \ldots$ are hydrodynamic parameters.

According to the practical situation, we suppose that the AUV moves with a constant velocity $u=u_{0}$, and the longitudinal motion equations of AUV can be described further [18]:

$$
\begin{aligned}
& {\left[\begin{array}{c}
\dot{z} \\
\dot{\theta}
\end{array}\right]=\left[\begin{array}{cc}
\cos \theta & 0 \\
0 & 1
\end{array}\right]\left[\begin{array}{l}
w \\
q
\end{array}\right]-\left[\begin{array}{c}
u_{0} \sin \theta \\
0
\end{array}\right]=A_{1}\left[\begin{array}{l}
w \\
q
\end{array}\right]-A_{\theta 1}} \\
& {\left[\begin{array}{c}
\dot{w} \\
\dot{q}
\end{array}\right]=M^{-1} u_{0}\left[\begin{array}{cc}
Z_{w} & Z_{q}+m \\
M_{w} & M_{q}
\end{array}\right]\left[\begin{array}{l}
w \\
q
\end{array}\right]} \\
& +M^{-1} u_{0}^{2}\left[\begin{array}{l}
Z_{\delta} \\
M_{\delta}
\end{array}\right] \delta_{s}+M^{-1}\left[\left(W-B_{0}\right) \cos \theta\right. \\
& \left.-\left(x_{g} W-x_{B} B_{0}\right) \cos \theta-\left(z_{g} W-z_{B} B_{0}\right) \sin \theta\right] \\
& +M^{-1}\left[\begin{array}{l}
Z_{d} \\
M_{d}
\end{array}\right]=A_{2}\left[\begin{array}{l}
w \\
q
\end{array}\right]+A_{\delta} \delta_{s}+A_{m} x_{\theta}+A_{d}
\end{aligned}
$$

where $M^{-1}=\left[\begin{array}{cc}m-Z_{\dot{w}} & -Z_{\dot{q}} \\ -M_{\dot{w}} & I_{y}-M_{\dot{q}}\end{array}\right]$.

The first-order wave force mainly affects the AUV during its moving near water surface. The first-order wave force, which is of high frequency and periodical, has amplitude 

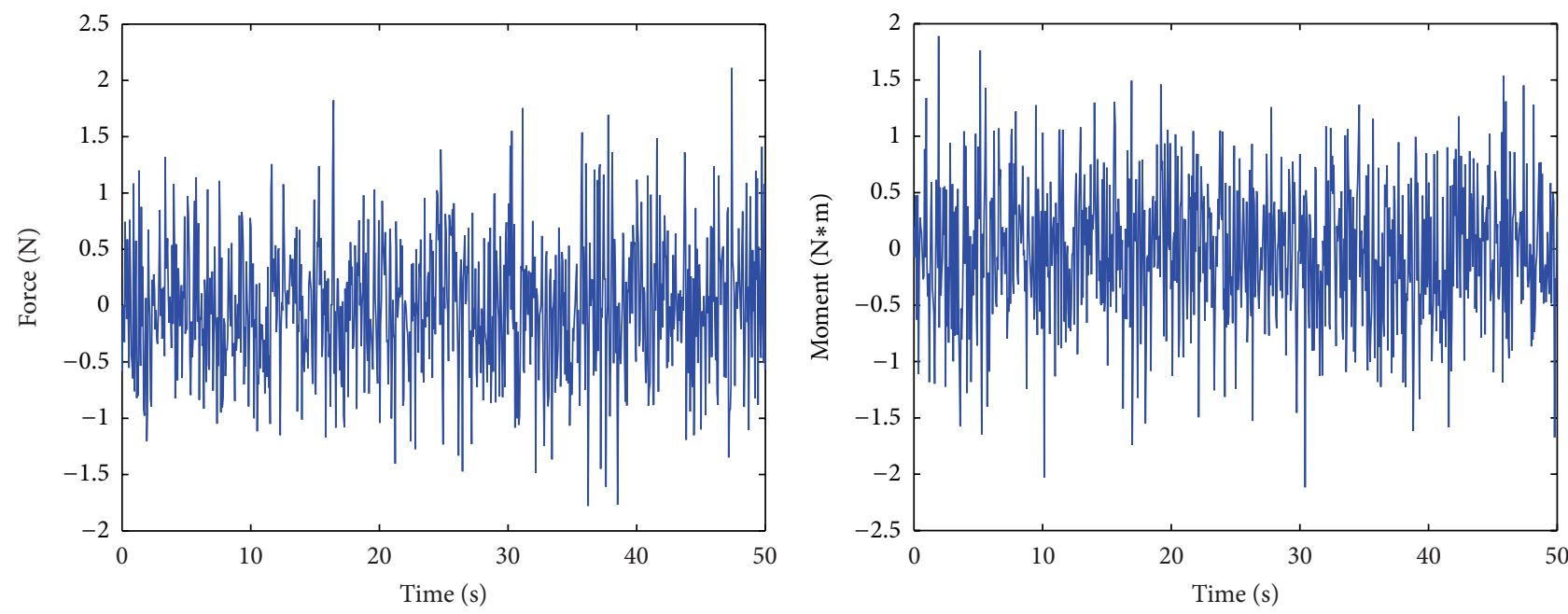

FIGURE 2: Wave force and wave torque.

proportional to wave height. In this paper, the Hirom approximation formula is adopted to calculate the first-order wave force and torque, and the concrete form is

$$
\begin{aligned}
& Z=\left(780-145 \sum F \sin \omega_{a} t\right) \sum F \sin \omega, \\
& M=1070 F \cos \omega_{a} t,
\end{aligned}
$$

where $F=a \omega^{2} e^{-\omega^{2}(H+h(t) / g)} ; \omega_{a}=-\omega(1-\omega U \cos \beta / g)$; $a_{i}=\sqrt{2 S(\omega) \delta \omega} ; h(t)$ is the wave height; $g$ is gravitational acceleration; $\omega$ is wave frequency; $\beta$ is wave to course angle; $h(t)$ is the distance between the AUV and sea surface. The first-order wave force and torque under the conditions that $H=10 \mathrm{~m}, u=2 \mathrm{~m} / \mathrm{s}$, and $\beta=0^{\circ}$ are shown in Figure 2, respectively.

From (5) and (6), the model can be expressed as

$$
\dot{x}=A x+B u+D,
$$

where state vector is $x=\left[\begin{array}{llll}z & \theta & w & q\end{array}\right]^{T}$, input is $u=\delta_{s}, A=$ $\left[\begin{array}{ll}O & A_{1} \\ O & A_{2}\end{array}\right], B=\left[\begin{array}{c}O \\ A_{\delta}\end{array}\right], \delta_{s}$ is rudder angle, and $D$ is the sum of disturbance terms and uncertain terms with wave force and torque.

\section{Design of Fuzzy Sliding Mode Controller}

The control of AUV, a typical underactuated system, is difficult in complex and variable underwater environment. Sliding mode control has the characteristic of discontinuity which forces the system to make a small range and high frequency sliding motion along a certain state. When the system is in the sliding mode, the control plant is invariant to uncertain parameters and disturbance. However, the invariance comes at the cost of high chattering, and it severely impacts the practical application of sliding mode control. It is one of the most effective ways to determine the switching gain in order to reduce the chattering by fuzzy method.
Let us suppose that the desired target state is $x_{d}=$ $\left[\begin{array}{llll}z_{d} & \theta_{d} & w_{d} & q_{d}\end{array}\right]^{T}$, and the control error is defined as follows:

$$
e=x-x_{d}
$$

The control target is to find a design of $u$ to minimize the control error. We choose the switching function as

$$
s=C e,
$$

where $C=\left[c_{1}, c_{2}, c_{3}, 1\right]$, which satisfies the Hurwitz stability condition.

With uncertain disturbance, we define the sliding mode control law as

$$
u=u_{\mathrm{eq}}+u_{s}
$$

where $u_{\mathrm{eq}}$ is the equivalent control and $u_{s}$ is the switching control.

Let us suppose that, after a period of time, the system reaches sliding mode surface, and, in an ideal situation, the control system will meet

$$
\begin{aligned}
& s=C e=0, \\
& \dot{s}=C \dot{e}=0 .
\end{aligned}
$$

The equivalent control is

$$
u_{\mathrm{eq}}=-(C B)^{-1}(C A x)+(C B)^{-1} C \dot{x}_{d} .
$$

We set the switching controller as

$$
u_{s}=k \operatorname{sgn}(s) \text {, }
$$


TABLE 2: Fuzzy table of output.

\begin{tabular}{llllllll}
\hline$s \dot{s}$ & NB & NM & NS & ZO & PS & PM & PB \\
\hline$\Delta k$ & NB & NM & NS & ZO & PS & PM & PB \\
\hline
\end{tabular}

where $k$ is switching gain; $\operatorname{sgn}(s)$ is sign function. Consider

$$
\begin{aligned}
& \operatorname{sgn}(s)= \begin{cases}+1, & s>0, \\
0, & s=0, \\
-1, & s<0,\end{cases} \\
& s \dot{s}=s[C \dot{e}]=s\left[C\left(A x+B u+D-\dot{x}_{d}\right)\right]=s(C A x \\
& \left.\quad+C B u+C D-C \dot{x}_{d}\right)=s(C A x \\
& +C B\left[-(C B)^{-1}(C A x)+(C B)^{-1} C \dot{x}_{d}+k \operatorname{sgn}(s)\right] \\
& \left.+C D-C \dot{x}_{d}\right)=s\left(C A x-C A x+C \dot{x}_{d}\right. \\
& \left.+C B k \operatorname{sgn}(s)+C D-C \dot{x}_{d}\right)=s(C B k \operatorname{sgn}(s) \\
& +C D) .
\end{aligned}
$$

Let $k=-\varepsilon(C B)^{-1}$, where $\varepsilon>\max (|C D|)$; thus $s \dot{s}<0$.

The reachability is verified. When the system enters into the sliding mode, it is effective to deal with the uncertain disturbance.

Appropriate switching gain can reduce the chattering efficiently. $s \dot{s}$ is the input, and $\Delta k$ is the output. Define both the fuzzy sets of $s \dot{s}$ and $\Delta k$ as [NB, NM, NS, ZO, PS, PM, PB], the universe is $[-3,-2,-1,0,1,2,3]$, and membership function adopts the triangle function. Fuzzy control rules are as follows:

(1) If $s \dot{s}>0, k$ should be increased.

(2) If $s \dot{s}<0, k$ should be decreased.

It is known that when the system goes out of the sliding mode surface, the switching gain should be increased to make the system reach the surface as quickly as possible; otherwise, if the system is on the sliding mode surface, the switching gain should be increased to reduce chattering. Fuzzy table of output is shown in Table 2.

Centroid method is adopted to achieve defuzzification, in which the enclosed area centroid by membership function and $x$-axis is calculated. We define $\mu$ as the fuzzy set of variable $x$; then the defuzzification result is

$$
\varepsilon=\frac{\int x \mu d x}{\int \mu d x} .
$$

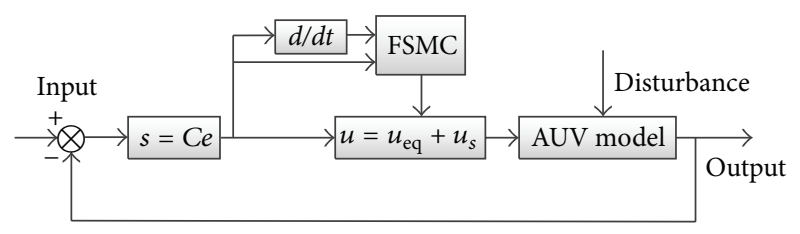

FIGURE 3: Diagram of fuzzy sliding mode control system.

We define the Lyapunov function as

$$
\begin{aligned}
V & =\frac{1}{2} s^{2}, \\
s \dot{s} & =s[C \dot{e}]=s\left[C\left(A x+B u+D-\dot{x}_{d}\right)\right]=s(C A x \\
& \left.+C B u+C D-C \dot{x}_{d}\right)=s(C A x \\
& +C B\left[-(C B)^{-1}(C A x)+(C B)^{-1} C \dot{x}_{d}+k \operatorname{sgn}(s)\right] \\
& \left.+C D-C \dot{x}_{d}\right)=s\left(C A x-C A x+C \dot{x}_{d}\right. \\
& \left.+C B k \operatorname{sgn}(s)+C D-C \dot{x}_{d}\right)=s(C B k \operatorname{sgn}(s) \\
& -C D) .
\end{aligned}
$$

Let $k=-\varepsilon(C B)^{-1}$, where $\varepsilon>\max (|C D|)$; thus $s \dot{s}<0$. Asymptotically stable condition is met.

\section{Analysis of Simulation Result}

The process of AUV longitudinal motion control is simulated to validate the effectiveness of this sliding mode control. The simulation environment is Matlab (R2011a)/Simulink, and the external disturbance is normal sea condition. Choose REMUS as the control plant. Hydrodynamic and physical parameters of REMUS when the AUV moves underwater are as follows:

$$
\begin{aligned}
& M_{\dot{q}}=-5.30 \mathrm{~kg} \cdot \mathrm{m}^{2} / \mathrm{rad} ; Z_{\dot{q}}=-2.24 \mathrm{~kg} \cdot \mathrm{m} / \mathrm{rad} ; \\
& M_{\dot{w}}=-2.35 \mathrm{~kg} \cdot \mathrm{m} ; Z_{\dot{w}}=-47.9 \mathrm{~kg} ; \\
& M_{q}=-23.2 \mathrm{~kg} \cdot \mathrm{m} / \mathrm{rad} ; Z_{q}=-26.6 \mathrm{~kg} / \mathrm{rad} ; \\
& M_{w}=15.9 \mathrm{~kg} ; Z_{w}=-45.6 \mathrm{~kg} / \mathrm{m} ; \\
& M_{\delta}=-6.51 \mathrm{~kg} / \mathrm{rad} ; Z_{\delta}=-6.51 \mathrm{~kg} /(\mathrm{m} \cdot \mathrm{rad}) ; \\
& x_{g}=0 ; y_{g}=0 ; z_{g}=0 ; \\
& x_{B}=0 ; y_{B}=0 ; z_{B}=-0.02 \mathrm{~m} ; \\
& W=363 \mathrm{~N} ; B_{0}=371 \mathrm{~N}
\end{aligned}
$$

The diagram of fuzzy sliding mode control system is shown in Figure 3.

Initial depth of AUV is $Z_{0}=0 \mathrm{~m}$, and target depth is $Z=$ $10 \mathrm{~m}$; initial pitch angle is $\theta_{0}=0.18 \mathrm{rad}$, and target pitch angle is $\theta_{0}=0.01 \mathrm{rad}$; initial pitch angle rate is $q_{0}=-0.01 \mathrm{rad} / \mathrm{s}$, and initial velocity along the $z$ direction $w_{0}=0.15 \mathrm{~m} / \mathrm{s}$. The switching function matrix is $C=\left[\begin{array}{llll}25 & 10 & 8 & 1\end{array}\right]$.

First, the sine wave response is used to test the performance of the controller, and the simulation result is shown in 


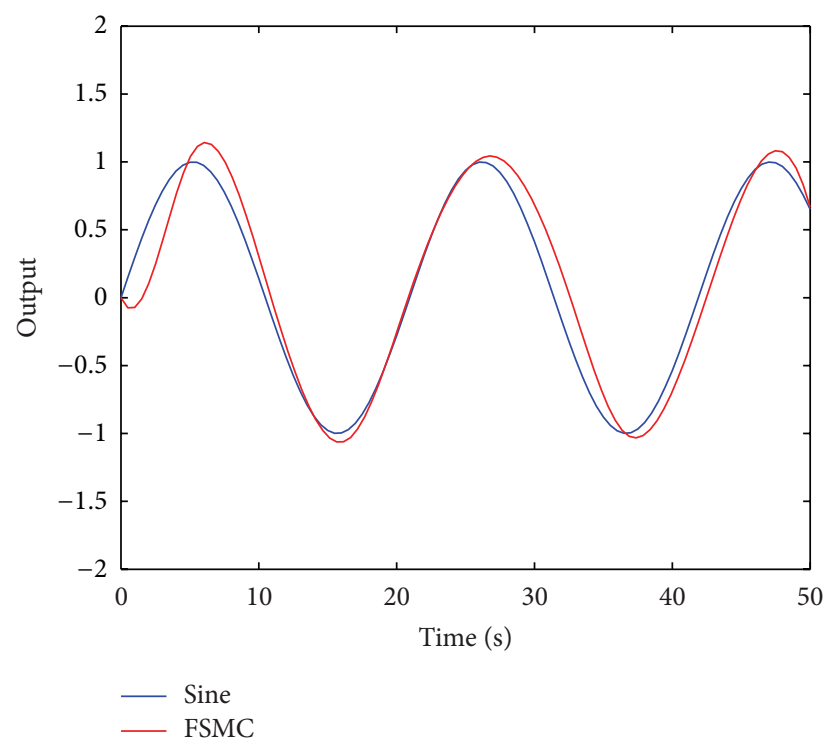

FIgURE 4: Sine wave response.
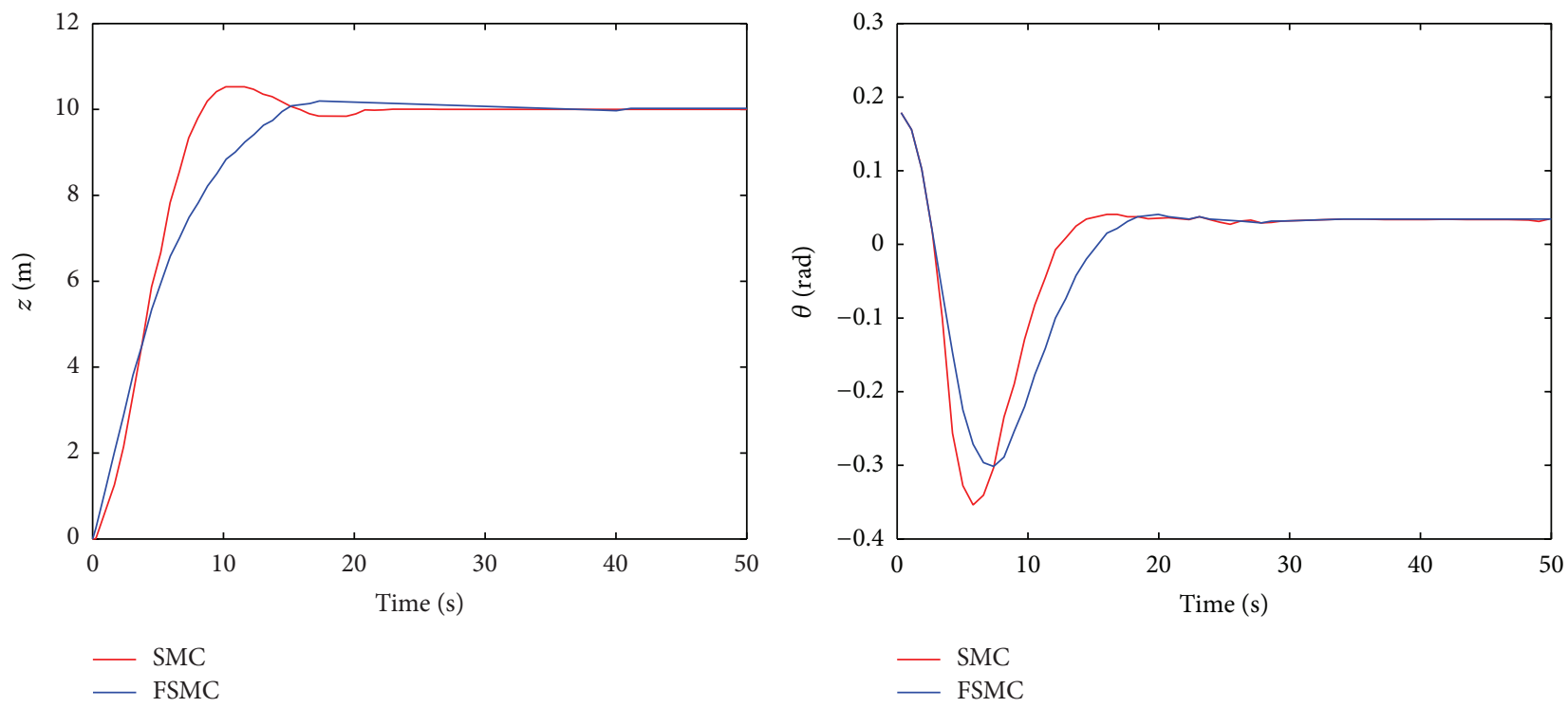

FIGURE 5: Changing curves of depth and pitch angle.

Figure 4. It can be seen that the fuzzy sliding mode controller has a good performance to track a varying state trajectory.

The conventional sliding mode control (SMC) and fuzzy sliding mode control (FSMC) are adopted, respectively, to control the longitudinal motion of AUV. The depth changing curves and pitch angle changing curve are shown in Figure 5, and the velocity changing along $z$ direction curve and pitch angle changing rate are shown in Figure 6.

As shown in the figures, under the normal sea conditions, both control methods are robust and can meet the requirements, which means that they can reach the control target and keep the system stable. Compared with conventional sliding mode control, fuzzy sliding mode control has a smaller overshoot and shorter adjusting time. Overshoot of SMC is about $18 \%$ while that of FSMC is less than $2 \%$; adjusting time of SMC is $25.53 \mathrm{~s}$ and that of FSMC is $19 \mathrm{~s}$. In addition, FSMC reduces the chattering phenomenon and control error, and the overall performance of FSMC is superior to that of SMC.

Figure 7 shows the changing curve of rudder angel. SMC has a longer adjusting time and bigger overshoot. A slight chattering will appear when the system reaches stable state. FSMC can adjust the horizontal rudder angles in a short time to reach steadiness without chattering.

\section{Conclusions}

A fuzzy sliding mode controller is designed to improve the control precision and antijamming capability of AUV in this paper, which combines the sliding mode control and fuzzy 


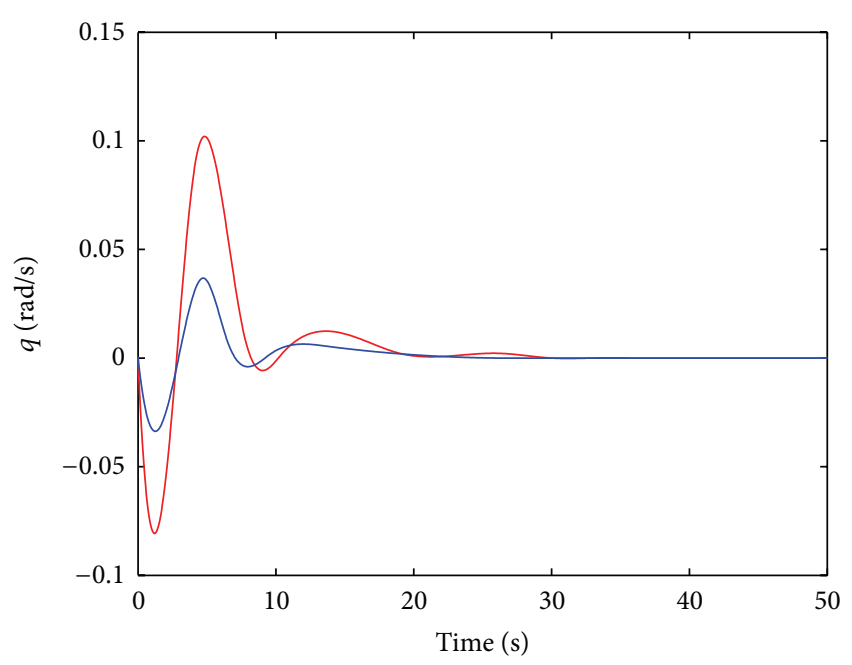

- SMC

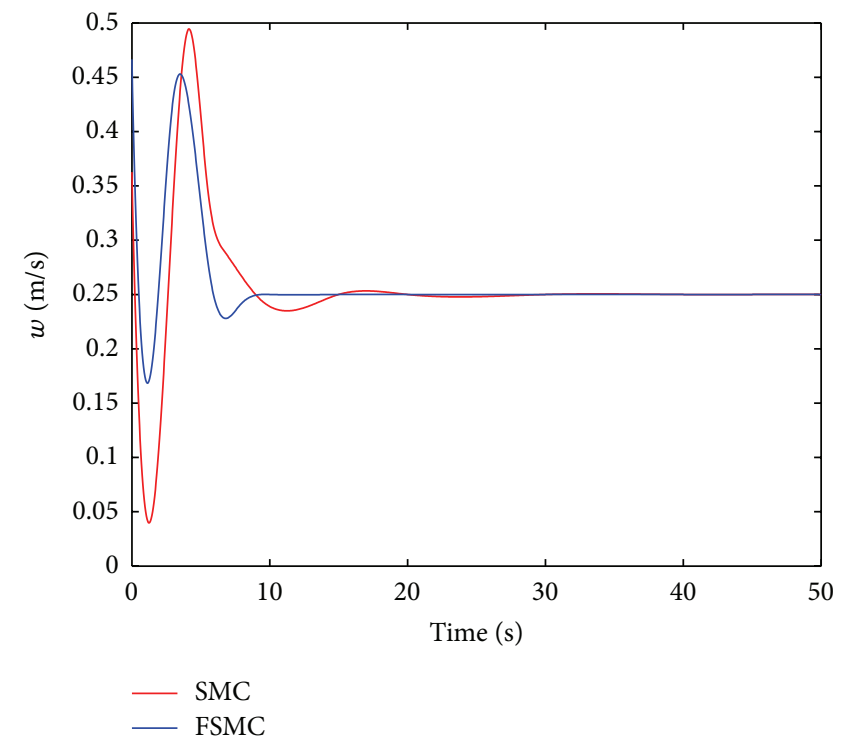

FIGURE 6: Changing curves of pitch rate and heave velocity.

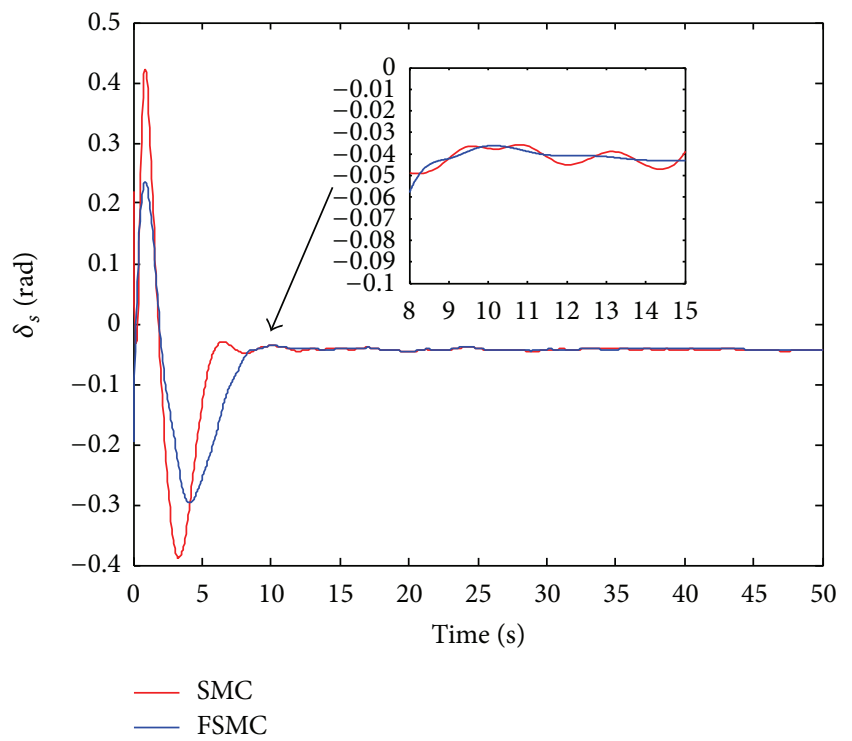

Figure 7: Changing curves of rudder angle.

control. Fuzzy rules are adopted to estimate the switching gain to eliminate disturbance terms and reduce chattering. The simulation results show that the fuzzy sliding mode controller can meet our requirements and has a higher precision and stronger antijamming performances compared with conventional sliding mode controller. In the further research, membership functions will be taken into consideration to improve the performance of fuzzy sliding mode controller.

\section{Conflict of Interests}

The authors declare that there is no conflict of interests regarding the publication of this paper.

\section{References}

[1] A. L. Forrest, B. Laval, M. J. Doble et al., "AUV measurements of under ice thermal structure," in Proceedings of the MTS/IEEE OCEANS, pp. 1-10, IEEE Press, Quebec City, Canada, September 2008.

[2] B.-H. Jun, J.-Y. Park, F.-Y. Lee et al., "Development of the AUV 'ISiMI' and a free running test in an ocean engineering basin," Ocean Engineering, vol. 36, no. 1, pp. 2-14, 2009.

[3] J. Petrich, C. A. Woolsey, and D. J. Stilwell, "Planar flow model identification for improved navigation of small AUVs," Ocean Engineering, vol. 36, no. 1, pp. 119-131, 2009.

[4] J. Jiang, B. Song, G. Pan, and M. Chang, "Study on design of shape and hydrodynamic layout for ultra-low-speed AUV," Torpedo Technology, vol. 19, no. 5, pp. 321-324, 2011 (Chinese).

[5] T. Li, D. Zhao, Z. Huang, and S. Su, "A method for selfestimating the depth of maneuvering AUV based on the grey particle filter," Journal of National University of Defense Technology, vol. 35, no. 5, pp. 185-190, 2013 (Chinese).

[6] B. Wang, L. Wan, Y.-R. Xu, and Z.-B. Qin, "Modeling and simulation of a mini AUV in spatial motion," Journal of Marine Science and Application, vol. 8, no. 1, pp. 7-12, 2009.

[7] L. Ma and W.-C. Cui, "Path following control of autonomous underwater vehicle based upon fuzzy hybrid control," Control Theory \& Applications, vol. 23, no. 3, pp. 341-346, 2006.

[8] H. M. Jia, L. J. Zhang, X. Q. Cheng, X. Q. Bian, Z. P. Yan, and J. J. Zhou, "Three-dimensional path following control for an underactuated UUV based on nonlinear iterative sliding mode," Acta Automatica Sinica, vol. 38, no. 2, pp. 308-314, 2012.

[9] B. K. Sahu and B. Subudhi, "Adaptive tracking control of an autonomous underwater vehicle," International Journal of Automation and Computing, vol. 11, no. 3, pp. 299-307, 2014.

[10] L. Lapierre and D. Soetanto, "Nonlinear path-following control of an AUV," Ocean Engineering, vol. 34, no. 11-12, pp. 1734-1744, 2007.

[11] Y. F. Peng, "Robust intelligent sliding model control using recurrent cerebellar model articulation controller for uncertain 
nonlinear chaotic systems," Chaos, Solitons \& Fractals, vol. 39, no. 1, pp. 150-167, 2009.

[12] D. Kim, H.-S. Choi, J.-Y. Kim, J.-H. Park, and N.-H. Tran, "Design of an underwater vehicle-manipulator system with redundancy," International Journal of Precision Engineering and Manufacturing, vol. 16, no. 7, pp. 1561-1570, 2015.

[13] X.-Y. Luo, Z.-H. Zhu, and X.-P. Guan, "Chattering reduction adaptive sliding-mode control for nonlinear time-delay systems," Control and Decision, vol. 24, no. 9, pp. 1429-1435, 2009 (Chinese).

[14] L. Zhang, Y. Pang, Y. Su, and Y. Liang, "HPSO-based fuzzy neural network control for AUV," Journal of Control Theory and Applications, vol. 6, no. 3, pp. 322-326, 2008.

[15] L.-X. Pan, H.-Z. Jin, and L.-L. Wang, "Robust control based on feedback linearization for roll stabilizing of autonomous underwater vehicle under wave disturbances," China Ocean Engineering, vol. 25, no. 2, pp. 251-263, 2011.

[16] S.-H. Ryu and J.-H. Park, "Auto-tuning of sliding mode control parameters using fuzzy logic," in Proceedings of the American Control Conference (ACC '01), vol. 1, pp. 618-623, IEEE, Arlington, Va, USA, June 2001.

[17] F.-J. Lin and W.-D. Chou, "An induction motor servo drive using sliding-mode controller with genetic algorithm," Electric Power Systems Research, vol. 64, no. 2, pp. 93-108, 2003.

[18] J. Cao, Y. Su, and J. Zhao, "Design of an adaptive controller for dive-plane control of a torpedo-shaped AUV," Journal of Marine Science and Application, vol. 10, no. 3, pp. 333-339, 2011. 


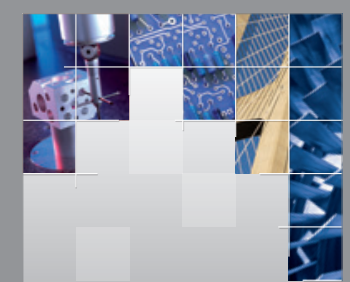

\section{Enfincering}
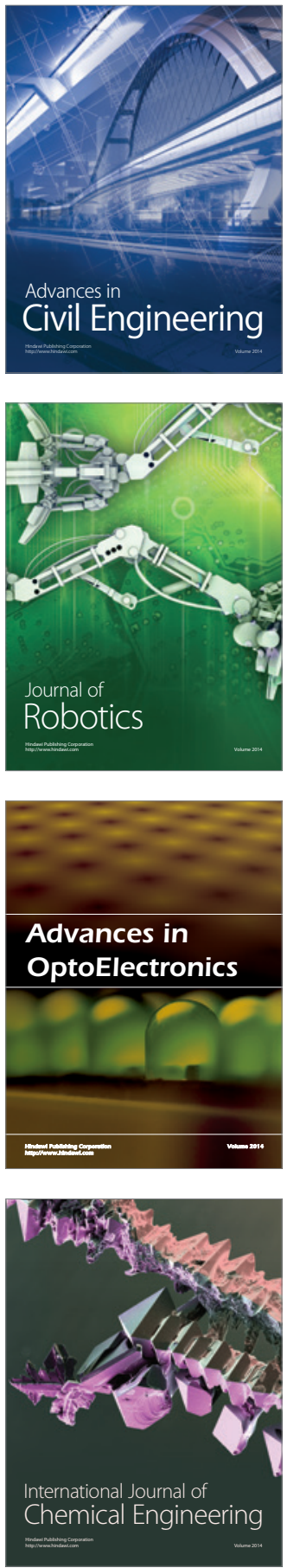

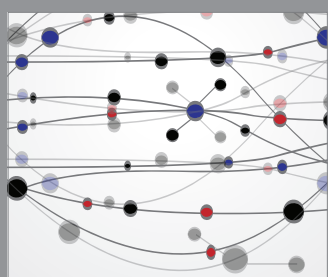

The Scientific World Journal

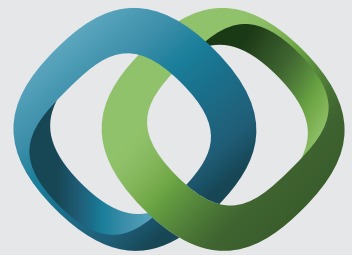

\section{Hindawi}

Submit your manuscripts at

http://www.hindawi.com
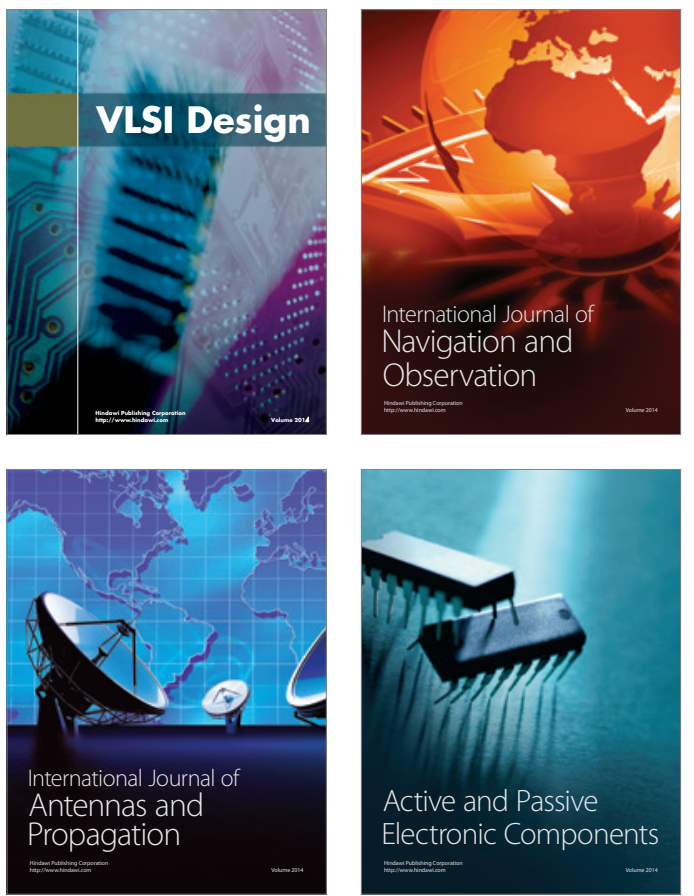
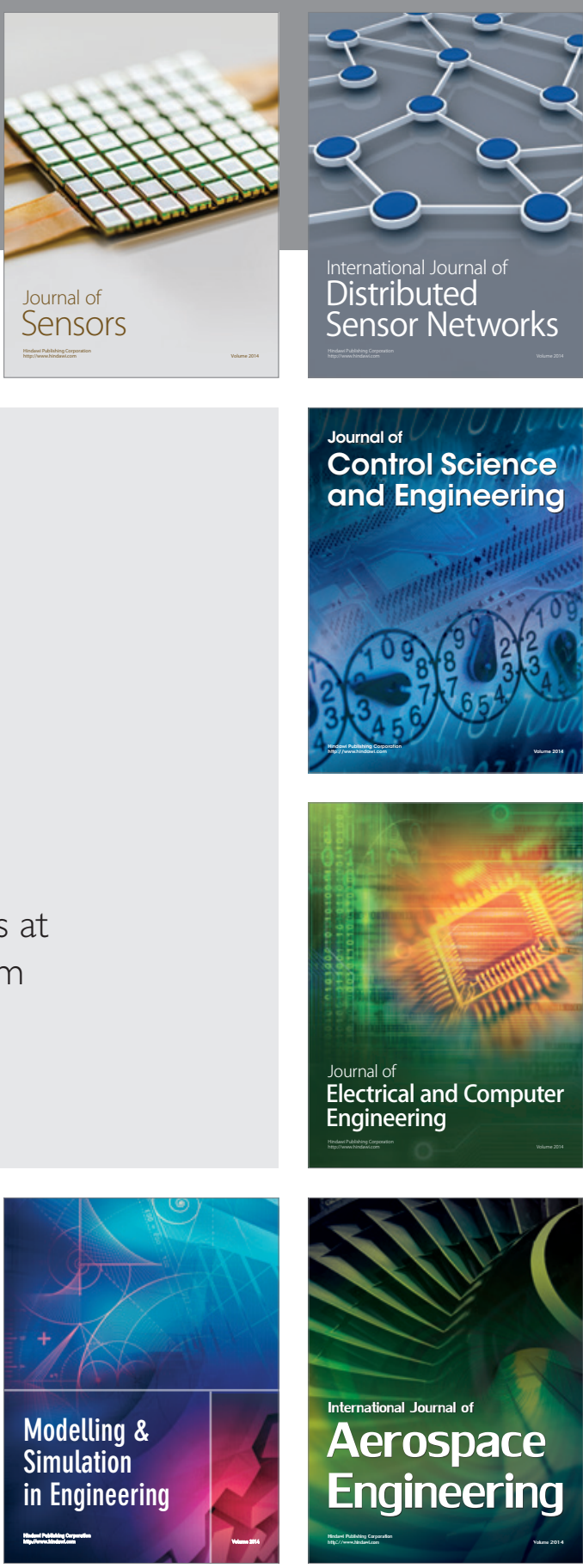

International Journal of

Distributed

Sensor Networks

Journal of

Control Science

and Engineering
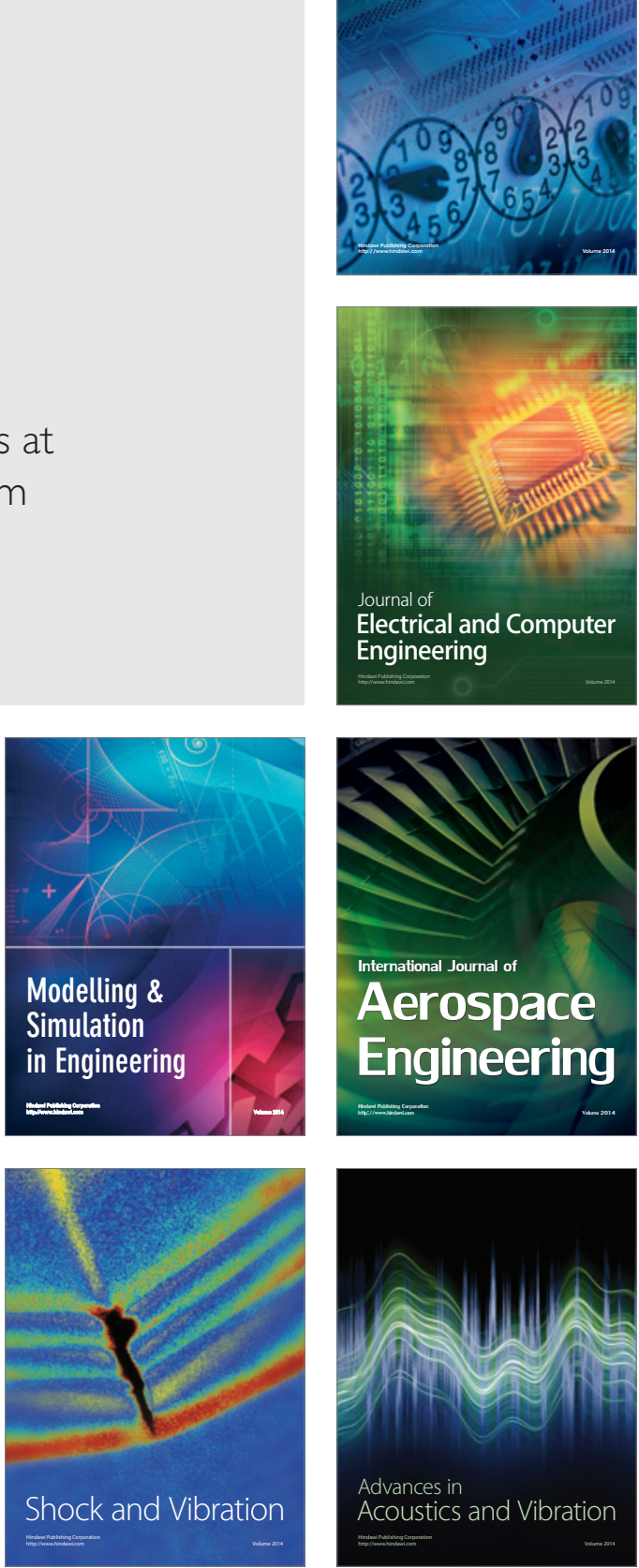